\title{
Islamic Manuscripts Art in Arabic and Persian Schools: The Artistic and Aesthetic Values
}

\author{
Fakhriya Al-Yahyai, Mohammed Al-Amri, Eslam Heiba, Heba Mansour \\ College of Education, Sultan Qaboos University, Muscat, Oman \\ Email: fakhriya@squ.edu.om,mhalamri@squ.edu.om, eslam@squ.edu.om,hebamansour@squ.edu.om
}

How to cite this paper: Al-Yahyai, F., Al-Amri, M., Heiba, E., \& Mansour, H. (2019). Islamic Manuscripts Art in Arabic and Persian Schools: The Artistic and Aesthetic Values. Art and Design Review, 7, 89-114.

https://doi.org/10.4236/adr.2019.72009

Received: March 4, 2019

Accepted: May 14, 2019

Published: May 17, 2019

Copyright $\odot 2019$ by author(s) and Scientific Research Publishing Inc. This work is licensed under the Creative Commons Attribution International License (CC BY 4.0).

http://creativecommons.org/licenses/by/4.0/

\section{Open Access}

\begin{abstract}
Manuscripts are known for their historical role as explanatory drawings for medical and literary manuscripts. However, the Muslim artist had initially recourse to this Art to speak about his reality including the daily life aspects and his spiritual world. Despite the richness of Islamic manuscript paintings and the prevalence of this Art practice by Muslim artists throughout several periods and eras, both the public and scientific interest are still very limited. This current research aims to determine the artistic and aesthetic values of the manuscript paintings in both Arabic and Persian schools. The goal is to contribute to appreciating manuscript paintings, revitalize the interest and develop their aesthetic and artistic aspects. Through this research we also discuss and analyze the differences between Arabic and Persian schools through selected models from both of them.
\end{abstract}

\section{Keywords}

Islamic Manuscript Art, Arabic and Persian Schools, Aesthetic Values of the Manuscript Paintings

\section{Introduction}

Islamic Art has started and spread quickly among the countries that embraced Islam. Then Art took different forms throughout History but it preserved its substance, its philosophy and aesthetics. It has been produced by artists from Syria, Egypt and Morocco and who deeply believed in Islam and assimilated its creed (Al-Sayg, 1988: p. 43).

The manuscript paintings were known to be one of the artistic orientations taken by Muslim artists in parallel with the translation movement that flourished during the Islamic conquests. It evolved to become one of the most distinguished Islamic Arts as it was related to the manuscript content. This helped in 
its easy expansion as it was considered as an important historical source to get to know the Islamic civilization history "as it has special and temporal dimensions and historical characteristics in addition to be considered as an artistic heritage" (Abdu, 1987: p. 92). However, although the artists have been captivated and amazed by manuscripts throughout several eras we still, they're still not interested in the theoretical study of manuscript Art. This research is to underline the need to study Manuscripts, and to define the aesthetic values for this Art in Arabic and Persian Schools.

\subsection{Research Problem}

- Islamic art is a rich discipline which included many traditional arts such as calligraphy, painting, glass, pottery/ceramic, textiles Metalwork and others. It is also well known by specific forms and characteristics such as Arabesque and Arabic calligraphy.

- With this richness, a large number of researches have been done in these traditional Islamic arts.

- However, the studies related to the Islamic Manuscripts are very rare.

- This study aims to contribute towards enriching the knowledge aspects regarding Art of Manuscripts with references to specific aesthetic principles of Arabic and Persian Schools that derived from the Islamic Heritage.

\subsection{Research Objectives}

This research tried to achieve the following research objectives:

- To define the impact of the Islamic thought on artistic styles and approaches adopted by the Muslim artist in the Manuscript paintings.

- To define the artistic and aesthetic values for appreciation Islamic Manuscript Arts.

- To provide an analysis for selected samples from the Arabic and Persian Manuscripts in terms of artistic, aesthetics values and Islamic culture and heritage.

\subsection{Importance of the Research}

The following points show the importance of the current research:

- To enrich the knowledge aspect of the Islamic Manuscript Arts.

- To refresh culture of Islamic art about the Islamic Manuscript and develop artistic aspects and knowledge regarding this traditional painting.

- Giving access to further studies and studies focusing on the Islamic Manuscript Arts. What is the impact of the Islamic view and thought on Islamic Manuscript Arts?

\subsection{Research Questions}

Through descriptive research method and deep discussion, this research tried to meet the following research questions: 
1) What are the aesthetic principles and standards for appreciation Islamic Manuscript Arts?

2) What are the artistic, aesthetic values and characteristics of the Islamic Manuscript Arts in the Arabic Schools in general and in Persian School in particularly?

3) What Analysis we could provide about Islamic Manuscript Art in Arabic and Persian Schools in terms of the Artistic, Aesthetic Values and Islamic culture appreciation?

\subsection{The Research Limitations}

This research treats only 12 works of art as models from both Arabic and Persian schools, each one belonging to an ancient civilization with a distinctive language and political and artistic history and heritage before and beyond the advent of Islam. These two schools have established the rules of Islamic manuscript painting with eastern character.

\subsection{Manuscript Definition}

A manuscript is a small painting on paper, whether a book illustration or a separate work of art intended to be kept in an album of such works called a Muraqqa. It was a part of the Islamic arts book, together with illumination (tezhip), calligraphy (khat), marbling paper (ebru), and bookbinding (cilf). The words Taswir or Nakish were used to define the art of manuscript painting.

\section{The Theoretical Framework}

In order to understand Islamic art, it is necessary to know the relationship between Islam as a religion and art in the Islamic world. This relation will give a deeper understanding about visual Islamic culture. Islam as a word means peace and Islam also means "devotion to God", more specifically to Allah, the one God; "those who practice such devotion and submit themselves to the will of Allah are Muslims" (Hattstein, 2000: p. 9). According to Al-Amri (2019a), In order to understand the history and philosophy of art in the Islam, it is necessary to recognize the relationship between Islam as a religion and art in the Islamic world. Al-Amri (2019b) confirms that "Understanding art and design education in this vast region is key to a deeper understanding and recognition of the relationship between Islam as a religion, on the one hand, and art as a discipline, on the other hand. Islam's fundamental tenet is that all Muslims must believe in one God" (p.3). This is mentioned on almost every page of the Koran. For example:

He who is God in heaven, is God on earth also he is the wise and knowing. (Sura43)

There is one God and he gives life and he causes death. (Sura44)

(The Holy Koran Book, Sura43 \& Sura44)

According to Al-Amri (2019b) the most important basic belief in Islam is that all Muslims must believe in one God and this is mentioned in almost every page 
of the Koran, the holy book of Islam, what God means to Islam:

- "He who is God in heaven, is God on earth also he is wise and the knowing" Sura43

- "There is one God and he gives life and he causes death" Sura44 (The Holy Book of The Koran, chapter 43 and 44)

Al-Amri (2019b) argues that

All Muslims everywhere follow the same tenets. While representation is prohibited according to the Islamic view, when it comes to making and representation through art, several points need to be clarified. First of all, the Koran does not make any direct reference to painting or sculpture or any kind of representational art. However, there are a number of unequivocal hadith (major sources of religious law and moral guidance uttered by the Prophet Mohammed and second only to the authority of the Koran) that seem to proscribe the art of making images or paintings for human beings. When it comes to representation, we find two examples of these hadith, which state the following:

Angels do not enter a house in which there is a representation [taswir] or a dog.

(Al-Bukhari, Al-Jami' Sahih, Hadith 4002)

The makers of images or representations [musawwirun] would be most severely punished on the Day of Resurrection.

(Al-Bukhari,Al-Jami' Sahih, Hadith 5957)

Therefore, musawwirun in the Arabic language means "image-makers", it means the "Fashioner, the Bestower of Forms, The Shaper, The One who is the fashioner and former of each and every thing in all of creation, The One who has given everything in creation a special inclination or desire, The One who has given everything a special form and a special manner whereby it is distinguished" (Shelquist, 2018).

As conclusion of this part, some of one could said that "Given the context of the primacy of God as al-Musawwir (he who makes and creates), one can begin to understand how these hadith would suggest that Islam discouraged art depicting human beings, especially painting and sculpture. As a result, these kinds of art forms became unlawful and were strictly for bidden" (Al-Amri, 2019a: p. 3). Therefore, Muslim artists were more forced on other type of arts such as Ceramic, Calligraphy, weaving, and architecture art. This also leads to adopting other kind of art such as Manuscript Arts as Islamic art identity, where the Muslim artists see their consolation in it as an alternative art making.

\section{The Impact of Islamic Philosophy on the Manuscript Arts}

Islamic Art doesn't aim to embody the physical beauty but to highlight the spiritual one that derives from the teachings of Quran. The Muslim artist is mainly interested in substance, and this has developed an aesthetic philosophy specific to Islamic Art. Islamic Art aesthetics derive from the philosophy starting from the artist's convictions and genius. In fact, the Muslim artist converts his vision 
of the Human Being into an independent and unique beautiful language. His work can be considered as a conceptualization for an aesthetic vision of the future. So, through Islamic Art the philosophy of beauty became an aesthetic material and spiritual philosophy. It takes the self to its highest level above materials in order to reach the substance and encourages the human being to always think and contemplate the creator's creativity.

Islamic representational art was worldly and not religious at all, it was implemented in practical art work and has not been introduced in mosques not to disturb the prayers. Islamic representational Art can be divided in two sections: The first one is the original model used in the manuscripts when drawing was a basic in medical, scientific and astronomical books. The second one is the traditional model used in textile, pottery, wall engraving and mineral art. However, the non-representational Islamic Art has spread widely and has been misunderstood and taken as a decorative art to be used instead of the representational art prohibited in Religious space. Recently, this has been understood and this art was henceforth clearly based on principles and renewable variables which are associated to philosophy, culture and environment. So the artist aims to reach abstraction and infinity through this art. Al-Sayg (1988: p. 43) supported that by saying "Nonrepresentational art has turned the surface into two abstractive dimensions, he tried to link real images with their rules and united substance. Nonrepresentational art is based on abstraction and the search for what the figure hides, and abstraction is one of the most important features of Islamic Art". For deep understanding about the history and philosophy of Islamic art in the Middle East and North Africa, see Chapter 2: "Art and Design Education in the Middle East and North Africa: A Brief Historical Overview" and Chapter 14: "Islamic and Other Influences on Art and Design Education in the Middle East and North Africa" for Al-Amri (2019a, 2019b).

Moreover, since the Philosophy of Islam is the main origin for Islamic manuscript Art, it has enabled the painter to reveal the soul of his civilization, taking into account its principles and traditions.

Moreover, the prohibition of representing live beings increased the interest in manuscript, so that the Muslim artist drew Human and mythic elements and animals with no personification. However, the represented elements always hide content and reveal special meanings according to the painter. For this reason, manuscript is said flexible and realistic.

The role of manuscript has been defined by the Islamic creed, and so on for all the paintings and Arts in the religious institutions. That is why Islamic manuscript is considered as a translation of symbolic and metaphorical messages. The role of the Muslim artist as Attia (1999: p. 107) clarify was "to convert temporal into non-temporal, through the use of transparency: instead of representing the shadow through lights, he represents the spread of lights in harmony and balance". While painting, the artist has been objective by focusing on the content itself, using a common language that he shares with the viewer. Topics were neither personal nor limited with space or time. The main goal was to clarify and 
explain the manuscripts, so the painter has used general human being elements (not personified) and never Humans with religious status. This means that the painters were not trying to explore their potential and competencies, their role was the same as in any other professional field. In fact, the painter used to sign with one of GOD's names then his.

The special characteristics of manuscript paintings as Izzat (2006) described was: "when employed paintings within the manuscript the works had a main role and a unique style, occupying a millimetric space within an unlimited framework, combined with the manuscript lines and style of representing elements is also unique" (pp. 39-38).

The Muslim artist distributed the elements harmoniously and combined material and spiritual, the religious and the worldly. So that Beauty embraced nobility and the way of representing live beings was modified and employed to express the absolute-which was the main goal of the Muslim artist. Moreover, Hanoura (1997) added that: "The employment of manuscript paintings within the manuscripts was a material space offered to the Muslim painter to express his thoughts and crystallize his imagination. However, the painter freedom was restricted, he had to review and take into account every detail, to draw his paintings in accordance with the handwritten text content and complete their shortages, by adding or erasing".

According to Al-Basha (1990), the impact of Islamic Philosophy on Manuscript paintings can be summarized in the following points:

1) Islamic creed has a main and a leading role in influencing Persian and Arabic manuscript paintings to go with the human nature. They include natural landscapes and human acts, which is a mean of entertainment, decoration, and the clarification of the manuscripts' content.

2) The representation being prohibited by Islamic creed led to the introduction of the manuscript within manuscripts.

3) Islamic creed enabled the painter to reveal his civilization soul through the nation's art works and practices.

4) Islamic creed led to a balance between material and moral needs, it makes Islamic Art unique comparatively to the previous civilizations. In fact, it was allowed to import the artistic heritage in the Islamic Manuscripts with modifications, to be in accordance with the Islamic creed principles. So that, the manuscript acquired characteristics that depend on the territory where it was practiced (Al-Basha, 1990: p. 228).

Sabri (2000) summarized the paintings' characteristics according to the Islamic creed in the following points:

- To exclude idolatry and polytheism from painting.

- To exclude any competition with God.

- Not to discourage the "Ummah" to be committed to their duties, and not to contrary the general benefit.

- Painting has to be a necessity.

- Painting only non-soul elements (Sabri, 2000: pp. 101-111). 


\section{The Artistic Values of the Islamic Manuscript}

\subsection{Philosophy of Space/Emptiness}

It was clear that the early Islamic painting was influenced by the local style of the conquered country. Then Islamic painting has spread in many countries starting from Syria, Iraq, Iran, Morocco, Egypt and Spain. Therefore, Islamic Art has developed distinct characteristics depending on the territory where it was practiced. Since Islamic Art is not based on figural representation and does not rely on the external aspects, the Muslim artist has transcended forms to reach the absolute, abstraction, and to show the "invisible". The manuscript painting Art was henceforth based on the same philosophy that aims to reach the abstraction. Moreover, the painter crystallized in his artwork the heart of the creed, for example, the unity of creation is based on the absolute and unique divine God.

Okasha (1977: p. 469) declared: “The Muslim painter did not ignore the dimensions of emptiness despite he could have exceptionally used them, he did not neither ignore the perspective basis and the third dimensional perspective drawing principles. However, he employed the virtual representation and relied on the intellectual truth of things without being committed with time, space or visual reality". Abu-al-ânin (2000) confirmed that "Accordingly, the painter relied on the two-dimensional-vacuum and so that achieved flatness in the majority of his designs. But he sometimes combined the flatness with the deep emptiness in the same time" (p. 17).

Manuscript paintings avoided of the rules of perspective and the third dimensional perspective, and even the light and the shadow. To express the depth of the vacuum, the artist employed combinations, and relied on the dimensions: the bigger character is represented the more importance he has. The figures are distributed in the space without considering dimensions. In fact, in many Islamic manuscript paintings the artists have sought to achieve the vacuum depth through flattening. As Bronowski (1981) has noticed "the existence of some manuscript paintings that reveal the use of the two dimensional-space and its representational levels" (p. 127), and Alam (1982) agreed that "The Persian artist is very keen on achieving depth by shifting rearward the skyline to enlarge the front space" (p. 223). She also spoke about the Taymuri school type (1982) in which the painters were very keen on achieving depth, representing details and sought to distribute effectively the characters in the space (p. 224), and she also referred to the most characterizes in the painting of the Mughal school; which divide the manuscript into a front part and a background (p. 241). Moreover, the Muslim artist sought to underline the depth of the vacuum by drawing hills in the backgrounds and characters behind. The main color he used was the dark blue and its gradations. He also drew architectural elements from different angles; and this led to a complicated organization of a flattened view (Alam, 1982).

\subsection{Relation between Language and the Figure}

The combination and relationship between the texts and the figure is specific to 
the Manuscript comparatively to the other Islamic Arts. This relation depends on the literal text and the geometric forms. The painter used to choose the forms after he writes the text that he aims to clarify. Therefore, the paintings become such mirrors that reflect the written and spoken message. Moreover, the manuscript elements and values derived from the literal words, in addition to the painter's ingenuity in the use of lines. In fact, Al-Basha (1990) declared that "the painters act like the calligraphers in terms of the use of lines, the consideration of proportions, accuracy and hand control for the line has a spiritual value in addition to the aesthetic one" (p. 235).

In other study, Al-Basha (1988) also summarized the role of Islamic manuscript paintings in the following points:

- Clarifying or comparing the text through the contemplation of the elements and the details' representation.

- Expressing with figures what is inexpressible with words.

- Relying on the image to prove and emphasize what is stated in the text (Al-Basha, 1988: p. 34).

\subsection{Balance}

The definition of the Balance according to AlNachar (1978) is: "The balance in distributing the plastic elements and geometrical unities. It is also the balance in the relationship between the elements themselves and between the elements and the intervals and the surrounding areas. This balance is ensured to build a coherent composition" (p. 36). Therefore, he considers the balance as one of the main important artistic values that the artist is keen on achieving. It is the case in every kind of Art, and particularly in the manuscript Art where the painter makes a balance between moral and material values, between the figure and the vacuum where the elements freely move with no crowd.

\subsection{Unity}

Al-Bahnasi (1997) quoted that pursuant to the Universe, Islamic creativity is subject to some rules and specific assets of terminology, for the meaning of "the full reality" is the absolute and the absolute is the truth of existence (p. 73). Attia (1997) argues that compatibility between parts guarantees the unity, then from unity emerges a group of elements in an organized current, such as the Whole, instance, or the entity dominating the details. In fact, according to El-Bassiouny (1994) unity means "The existence of a dominating whole, beyond the simple details. In fact, the painter uses his energy in drawing lines, linking and combining the scattered parts that start gradually taking features. This is the result of the soul that the parts and details acquired within the new whole" (p. 21).

Through compatibility between the elements, the work acquires total coalition and leads to a homogeneous entity made of forms linked by similarity, proximity, alignment and continuation.

Feeling this unity, the Muslim artist tried to embrace the absolute in order to 
reach unity in his work, by including spirituality and deep contemplation. For this purpose, he also employed the elements effectively with a balanced distribution and harmonic combination and used lines, axes, spaces and elements. This has led to a mixture between the figure and the content in one unity.

\subsection{Proportion and Proportionality}

Normally, Dimensional and perspective rules are based on the relative decline which relies on the decrease or atrophy of the elements, on the colors' intensity, or on the impression of distance separating them from the viewer. Although Muslim painters were not used to these rules, the viewer could perceive in their paintings the three dimensions, and this strengthened the illusion of proportion and proportionality in the Manuscript plane. In fact, Anani (1998) explained that: "Proportionality is an artistic value deriving from the organization of forms and elements in the manuscript, for organization defines the artistic role of each part of the Islamic manuscript" (p. 16).

\subsection{Rhythm}

The Muslim artist has been keen on achieving the value of the rhythm whether regular or varied, in his manuscript paintings. This variation is revealed by the horizontal and vertical lines used in architectural installations with diverse lengths and directions, as well as by the curved and soft lines employed in the features of human faces and vegetal patterns.

The value of rhythm was achieved when distributing the Human being representations through the body members' movements as well as transition from Human to architectural elements. In fact, the artist reached the rhythm by linking the Human elements to the architectural backgrounds. To link them he employed the circular halos above Human heads, reminiscent of circular forms in the buildings. Moreover, this value was achieved through the distribution of the space between manuscript areas and literal texts as well as the colors and the architectural elements.

Finally, the previous discussions can be considered as an answer to the first question of this research: "What are the aesthetic principles and standards for appreciation Islamic Manuscript Arts?" They can be summarized in the following Islamic manuscripts' artistic values: Philosophy of the Space, the relationship between the language and the figure, Balance, Unity, Proportion and proportionality and rhythm. Moreover, the Islamic manuscript is characterized by: the artist's inspiration from the heritage and from live beings' elements and the texts, the artist keenness on representing figures and characters with no personification, the compatibility between the employed font in the literal texts and the elements in the illustration, and many other standards.

\section{Artistic and Aesthetic Values of the Islamic Manuscript in Arabic and Persian Schools}

In order to answer the second question "What are the artistic, aesthetic values 
and characteristics of the Islamic Manuscript Arts in the Arabic Schools in general and in Persian School in particularly?", the researchers would like to provide the following discussions about the main characteristics of both Arabic and Persian Schools. First we will focus on Arabic Manuscript and then following by the characteristics of Persian schools.

\subsection{Arabic Manuscript Characteristics}

According to Farghali (1991), since the $6^{\text {th }}$ century Hijri, the Arabic School has assisted a boom in the decoration of the colored manuscripts. The Art spread through local laterals in the whole Islamic world, and mostly launched from Iraq (Bagdad, Mawsil, Kufa, Basra) to reach Syria and Egypt.

Manuscript paintings' main role was to emphasize and explain the manuscript content, and not to show the artists' talents. In fact, some of the manuscripts were decorated with very small images respecting the free space left by the calligrapher. There are no frames or limits separating the manuscripts from the manuscripts' content. So the writer provides the calligrapher with the text that he copies with his handwriting. And he leaves free spaces for the painter to draw accordingly to the topics and stories.

Arabic Manuscript characteristics were summarized by Farghali (1991: pp. 84-86):

- "Because of the religious stricture on the representation of nature, the Islamic Art eschews the realistic representation. In fact, the painter represented the Human being with a different style. He neglected the body details and focused on revealing the main character at the forefront at the expense of secondary characters.

- Absence of depth and coalition: The artist neglected some artistic basis that serve to expressing depth such as lights and shadows. Therefore, he obtained very enlightened paintings even for night-representations. So night was only visible through the moon and the stars. The artist didn't even employ the colors degradation and used brilliant colors only.

- The painter added in golden color Halos around the characters and birds' heads and around flowers. The purpose was not to symbolize the sacred but to underline the importance of every painted element and to draw attention to it.

- Burying in the decoration in order to eschew the realistic representation. This is revealed by the use of cheerful and brilliant colors, the lack of colors' degradation, as well as the decorative architectural backgrounds covered by floral and geometric designs.

- The majority of Arabic Painters have been tinting their paintings' backgrounds in golden color.

- Simplicity and absence of complexity was one of the main characteristics of Arabic Art. In fact, the paintings were not separated from the content by limits or frames. In addition, the architectural and floral backgrounds, the rocks and hills were represented in a very simplified way with a mostly decorative 
tendency.

- Aligning the elements on a broad or fine line, and sometimes using the inferior painting frame limit, or painting a line made of leaves and from which emerge trees, flowers and plants' branches.

- Faces' features were dominated by the Arabic aspect, especially the Human faces which reflected sublimity. These aspects were visible in the black beards, the oriental and Arabic clothes, mostly large and loose. They were adorned with similar floral designs, flowers or geometrical elements like in the manuscripts of 'Kalila \& Dimna', maqamat al-Hariri, and al-Asfahani Book of Songs.

- In the Arabic uniforms, adornments are crystallized in the represented details and the fonds, the use of lines and geometrical elements, the representation of animals, flowers, castles and halos even the Arabesque. Painters have been tending to get closer to reality when they drew the clothing folds emerging from one center or in curved lines. So the painter togs his characters Arabic uniforms from the turban that cover the heads, to the short Djelbab and long trousers.

- Painting relatively small horses especially in lateral positions and tinting them in blue, green, pink, purple, red, black and golden color.

- Animals were employed in the manuscript criticize ironically the social situation and the ruling class, or for sharing advice and wisdom. So the painter provided 'the animal with the ability to speak'" (Attia, 2005: p. 146).

\subsection{Persian Manuscript Characteristics}

According to Bosworth (1996), all the archeologists and Islamic Art scientists agree that Islamic Painting Art has passed through different steps that led to the apparition of the Taymuri School in Iran since the late eighth (Hijri) and Fourteenth (a.d.) century, until the early tenth (Hijri) and sixteenth (a.d.) century. (22) The Persian territory especially Chiraz city has assisted a flourishing era under the governance of the Mudhafaris' family, it is the case for Bagdad and Tabriz under the governance of Jalairis' family. Each one had special characteristics, the following are the Mudhafari's:

- The apparition of two kinds of backgrounds in Persian manuscript paintings: The first one is: Backgrounds filled with civil buildings (houses and palaces), and war buildings such as forts and castles These backgrounds were all painted in a simple style showing the principle entry and the windows, with balconies above, texts written above the entry and on the walls saying "Sovereignty to God".

- The second kind is: Backgrounds adorned with floral designs, harmonic bouquets of grass and flowers, including high rocky hills painted in a spongy style. And the floors were sometimes divided into different levels (Al-Basha, 1988: p. 319).

- The front fore has been enlarged at the expense of the fond which represents the sky and took a secondary role. The elements were distributed with no re- 
spect of the basis of dimensions and perspective. The use of the Bird's eye perspective showed all the elements from the top, which has led to a lack of depth and a flattened manuscript.

- The main character was usually represented in the center, sitting on a chair or a throne without taking into consideration the body proportionality and details. The secondary characters were usually surrounding him/her.

- Animals' representation was very close to reality especially the horses'.

- Clothing were diverse, the constant element was the Turban that covered especially the main character's head.

- In the Persian Manuscripts, the painters employed brilliant colors such as: Red, yellow, green, purple, golden color, blue. This reflected joy and cheer (Al-Basha, 1988).

\section{Technical Ores and Materials Used in Manuscripts}

The latest scientific studies have contributed in identifying the materials and the ores used in Persian and Arabic manuscript paintings, in terms of paper industry, dye and carpets, as following:

1) Paper: There were different classifications, in fact, Ibn Nedim classified the paper in seven kinds: Khuraseni, Solimani, Talhi, Nahwi, Pharaonic, Jaafari, Dhahiri (Hamouda, 1994: pp. 81-82). At the same time Mehrez (1962) relied on three kind classifications: gilt paper, paper adorned with gold, marbled paper, cloud color paper from the simple, the combed, to the complicated, the flowered.

2) Paper dough: it is made of small pieces of silk left in water. They turn into a smooth dough and dry to turn into a light paper. This product was expensive until new materials have been discovered such as plants' pips, cotton waste and old trawls. Since then, Muslim and Persian paper industry has flourished, and painters started using papyrus for their manuscripts.

3) Paper preparation: After it dries, the paper is polished with a wide brush using the egg white or dissolved starch to occlude holes and to avoid the colors' adsorption. Then the paper is left on a backboard after curving it with a hard rock, an oyster or glass. This strengthens the paper and polishes it.

4) Colors: The painter was able to compose three groups of pigments from different sources: Mineral colors, organic colors, non-organic manufactured colors. Mineral and organic colors were the most prevalent in manuscripts' era, and very similar in their preparation. Arab and Persian Muslim painters opted for Mineral ones for the following reasons cited by Mehrez (1962): dark and non-transparent, preserve color and grade, don't turn into a secondary color when mixed together, and the color solvent (egg white, glue, Arabic glue) preserves the color and protects it from humidity. However, Mineral colors have disadvantages such as: oxidation due to the weather, erosion of the paper edges due to which many Persian manuscript paintings were lost. Mineral colors are basically composed of:

- Red with its different grades: red vermilion, bright red, orange bright red and 
reddish-brown.

- White: white lead, or smooth chalk.

- Blue: dark blue (Azure).

- Yellow: from yellow plumbi oxidum.

- Green: from Azurite.

- Black: obtained from Boiled coal with walnuts.

- Purple: mixture between yellow and Indian Carminum.

5) Materials:

The same materials are used for painting and writing, they have been defined by Mahmud Abbas: Pencils, inkstand, a penknife, a watering pan, a polisher, a sander, a cloth, a ruler, a vice, glue, outrigger, brushes (Hanoura, 1997: pp. 59-65).

\section{Analysis of Islamic Manuscript Art in Arabic and Persian Schools}

To answer the third question "What Analysis we could provide about Islamic Manuscript Art in Arabic and Persian Schools in terms of the Artistic, Aesthetic Values and Islamic culture appreciation?", the painting Manuscripts have been analyzed accordingly to the Islamic literature associated with the artistic and aesthetics of Islamic Art in generally and Islamic Manuscript particularly. The analysis is staring within the Arabic manuscripts and then followed by Persian manuscript which each analysis associated with figures representing the painting of the manuscripts as the following.

\subsection{The Arabic Manuscripts}

Figure 1 is a painting of camels which is one of Al-Hariri's tale manuscripts kept in Paris's National Library, copied and decorated by Yahya Bin Mahmoud Al-Wasti (H. 634 /A.D.1237).

The artist portrayed a rural view of a person standing by ten she-camels on a ground painted in a form of a broad green line from which modified grass and plants emerge. The manuscript represents a picture of shepherd and a herd of camels in different simulated postures where some necks appear rising high, and others pointing down to pick up grass. The artist has distributed his elements over the ground-line in the form of a horizontal matrix. He has also distributed the copying writings up and down the manuscript to present proverbs and advice concerning the cruelty of time since he has used the camel element to denote sublimity and dignity. He has expressed the cruelty of time through the camels lowering their sublime heads to stress the expressive content of the manuscript text.

The artist painted the shepherd's character with Arabian features represented by the Arabian style which is characterized with loose costumes, broad sleeves, the Arabian turban and the Arabian countenance that appeared in a simple, surfaced shape to stress the non-personification element within the manuscript. The Muslim artist depended on the absolute space in distributing his words in 


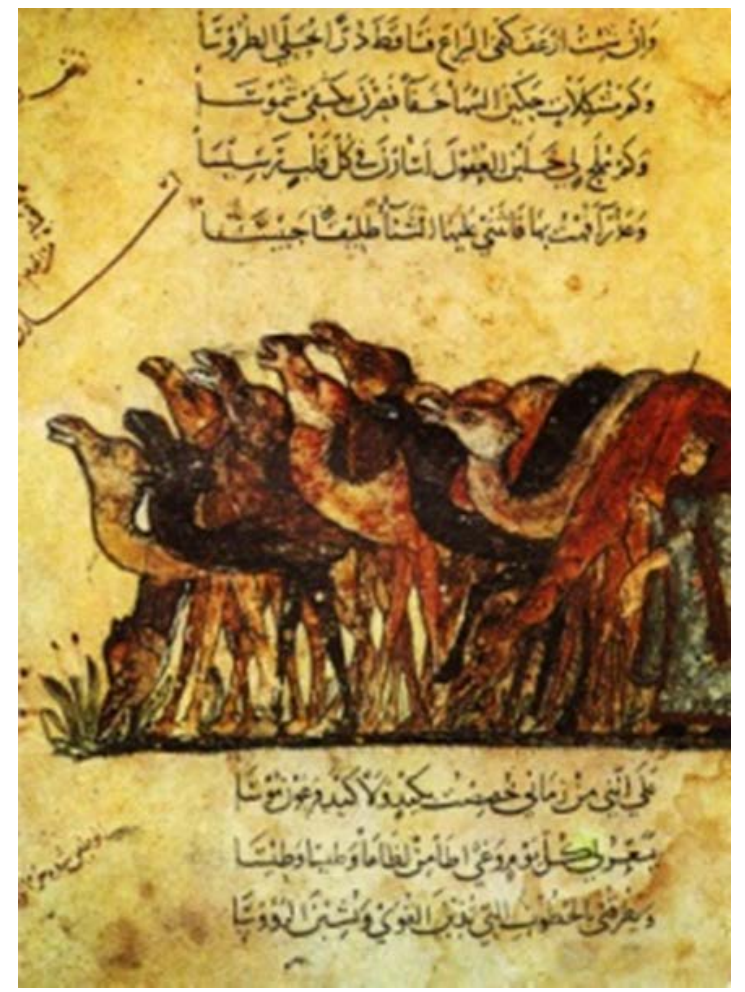

Figure 1. Camel Herd Painting: From maqāmāt al-Harīī (assemblies of Al-Hariri), La bibliotheque nationale de Paris, illustrated by Yahya ibn Mahmud al-Wasiti (643 Hijri/1237 A.D.).

the middle of the manuscript to express artistic values from an Islamic perspective. He also expressed it through the repetitive and balanced rhythm of the Arab calligraphy's words. The uniqueness of the manuscript lies in the choice of one animal element and repeating it harmonious, coloured and formal rhythms creating a simultaneous formal and coloured unity. The artist also stressed the ratio and proportion when dealing with the camel element since all the camels appeared in similar sizes, but there was a difference lying in their heads' acting movements to stress the dynamics of movement inside the manuscript, and the correlation existing between them and silence and statics in the horizontal matrixes of calligraphic and copying writings. Furthermore, the variety in the colour processes resulted in creating unity and diversification in the work of art. Equilibrium was achieved within the manuscript through the good distribution of the animal and human elements over the ground line in the middle of the manuscript and the writings in the copying calligraphy represented by a picture of horizontal matrixes, too.

Figure 2 is a painting of the pilgrimage procession from Al-Hariri's tale manuscripts.

This is a painting representing a pilgrims' caravan with groups of camels in a variety of movements, with the movements of flags and people who are beating drums and blowing trumpets as a sort of celebrating the pilgrims' return. The artist also singled out the main character by decorating its own howdah. The 


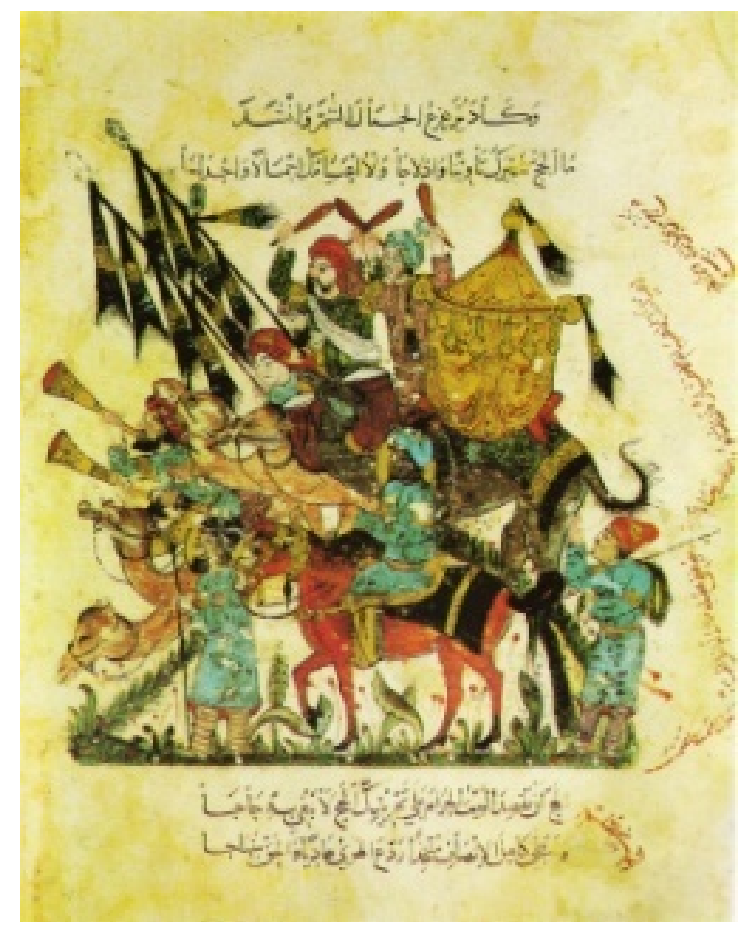

Figure 2. Hajj Parade painting, from Maqamat al-Hariri manuscripts.

artist distributed the manuscript elements to occupy three quarters of its area spread over the ground line in a picture of a horizontal matrix. The remaining quarter is occupying the copying writings distributed in horizontal positions up and down the manuscript, and in a sloping shape on the left side of the manuscript. Moreover, the artist worked to achieve ratio and proportion among the painted elements; the ratio existing among the camels is proportionate. Similarly, there is proportion between the size of howdah and the camel carrying it. The colour harmony was achieved through the good frequency of the glossy colour spaces of red, green, blue and gold. The artist's interest in the dynamic rhythm appeared through diversifying the positions and gestures of the human and animal elements in addition to flags and trumpets. This realizes unity among the manuscript elements, which demonstrates its uniqueness in presenting its elements. The paintings stressed the expressive content of the copying writings. The manuscript is characterized with dynamics and movement resulting from the diversification of the acting positions of the elements and their movements in addition to colour diversification of human and animal elements. In general, the elements were characterized with superficiality and simplification to stress the non-personification aspect of manipulation.

Figure 3 is Abi Zaid's and Al-Harth's farewell-from Al-Hariri's tale manuscripts.

The portrait shows Abi Zaid and Al-Harith riding camels in a confronting status for farewell. The main characters appear at the front of the manuscript in Arabian garments with different folds. Abu Zaid appears in an advanced age status compared with Al-Harith's age wearing a dark-colured gown while 


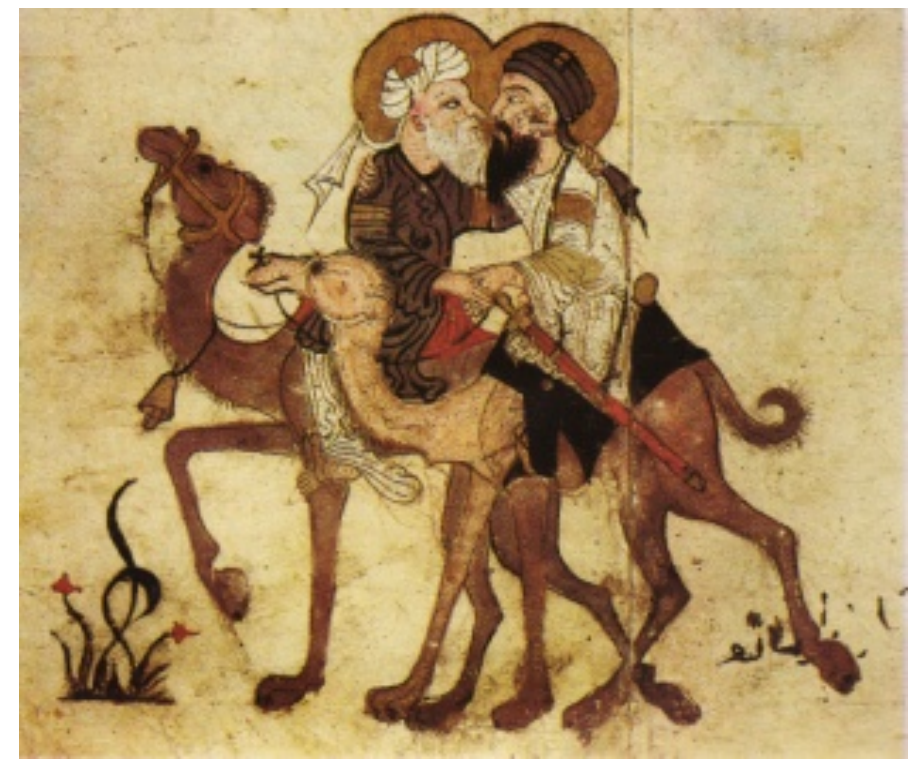

Figure 3. Abu Zeid and al-Harith farewell, from Maqamat al-Hariri manuscripts.

Al-Harith appears in a light-coloured dress. The artist's emphasis on the element of dynamics and motion appears in the contiguity of hands and the motion of clothes that appear circularly above the arms and the motion of the camels' legs, and in spite of that stillness and superficiality appear in handling the whole of the manuscript. The fact that the bodies of Abi Zaid and Al-Harith are occupying the space of the whole manuscript means the negation of having ratio and proportion between them and the other elements represented by simple grass on the left side of the manuscript and surrounding space. However, the artist is keen to create equilibrium of form and colour through the contiguity of the two main characters in the motion of hands and feet, the contiguity of the two faces, the diversity in the colour of costumes and the colour handling of camels. The artist also takes care to achieve unity of colour and form through contiguity and the embracing of the two main characters occupying the centre of the manuscript.

Figure 4 shows that Bayâd singing the praises of his love, being surrounded by a group of women, from the manuscript "Bayâd wa Riâdh", in the Vatican library $\left(8^{\text {th }}\right.$ century Hijri/14 $4^{\text {th }}$ century A.D.)

The painting shows Bayâd in one of the gardens' yards singing the praises of his love and playing the Lute, covering his head with an Arabic turban, decorated with a golden color band. A group of women are surrounding him. Being in three quarters face pose, their features seem similar to the mural and fresco Fatimid paintings. On the left is sitting a princess with a golden crown, showing Bayâd with her right-hand. Two other women are holding glasses for both Bayâd and the princess. The floor is represented with a board line made of green grass from which emerge two trees drawn in the Arabic style. On the extreme right and left appears an architectural background. It is clear that the dimensions and perspective basis have not been taken into consideration so the elements seem 
simplified and flattened. However, the painter sought to achieve unity of forms and colors by distributing the Human elements in the Manuscript's center, although he didn't rely on proportionality between them and the buildings. Finally, the painting emphasizes the text content that treat a social sentimental topic.

Figure 5 is a picture representing Abi Zaid Al-Sorooji and Al-Harith Ibn Hammam in front of one of Morocco's mosques-from a manuscript of Al-Hariri's tales.

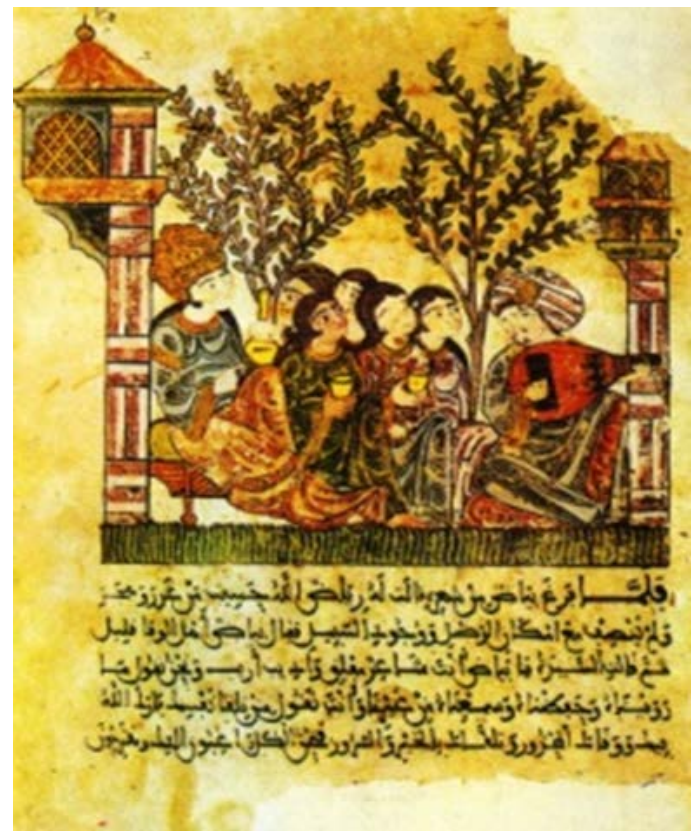

Figure 4. Bayâd singing the praises of his love, being surrounded by a group of women, from the manuscript "Bayâd wa Riâdh", in the Vatican library $\left(8^{\text {th }}\right.$ century Hijri/ $14^{\text {th }}$ century A.D.).

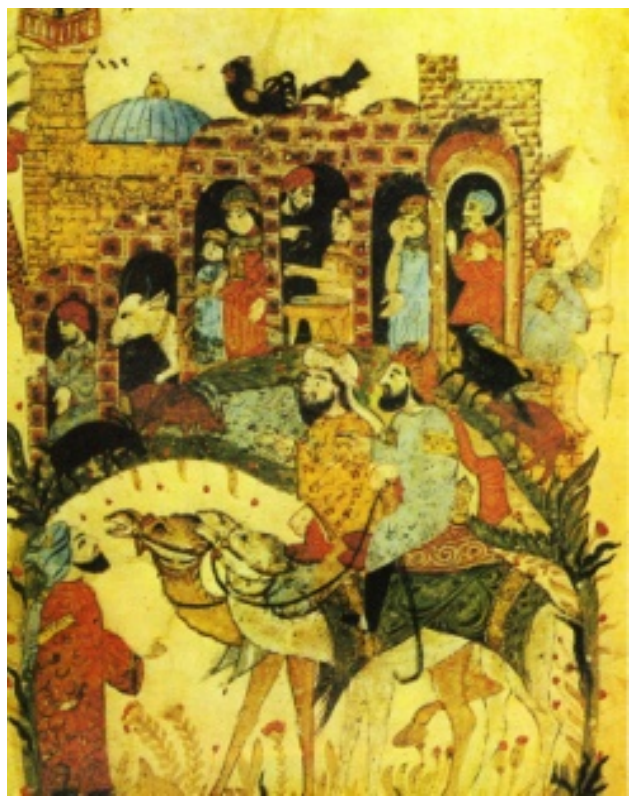

Figure 5. Painting showing Aba Zeid al-Suruji and al-Hareth Ibn Hamam in front of a mosque in el-Maghreb, from maqamat al-Hariri manuscripts. 
The picture shows Abu Zaid Al-Sorooji and Al-Harith Ibn Hammam in front of a mosque in Morocco riding camels. The main characters appear at the front of the manuscript in an ornamented colourful dress and an Arabian turban while another person is standing in front of them in a different dress with less arabesque. The artist tackled the manuscript rear using Islamic buildings with hemispheric necklaces, and there are a mosque's minaret and dome nearby. The uniqueness of the manuscript lies in the combination of time and place through the presence of the cock which symbolizes times of prayers. Apart from the mosque rear, there are buildings in the balconies of which a group of women and men appear in various, simplified acting postures. Besides, the artist lays stress on the space behind the two main characters to lessen the accumulation of the elements in the manuscript rear, which reduces the artist's interest in the ratio and proportion between the two characters at the front and the rest of people and their relationships with the buildings in the rear. Thanks to the proper distribution of the human, animal and architectural words in frequent forms and colours, the artist succeeds in furnishing the manuscript with a total unity of its elements. The artist balances between positioning statics at the manuscript front represented by the two main characters and the dynamics in the different acting postures of people, buildings and the manuscript rear. Apart from that, the artist's use of the golden colour has a positive role in linking the elements at the manuscript front with those at the manuscript rear.

Figure 6 is a picture representing Badr Addein Lulu in a mirth setting-from

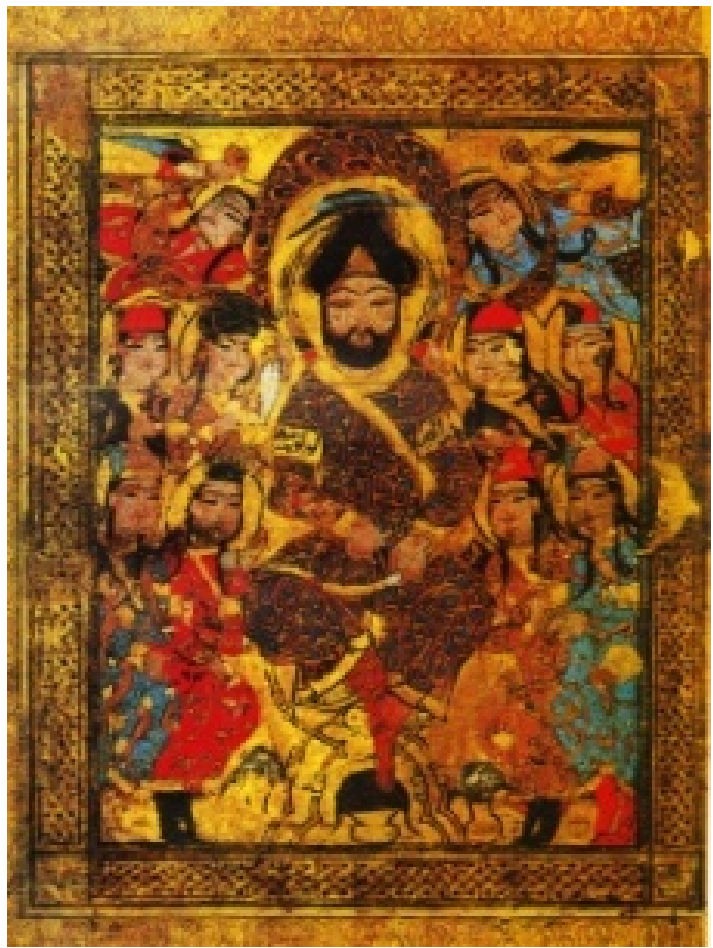

Figure 6. Badr al-Din Lulu in a singing majlis, from Abu'l-Faraj al-Isfahani's Kitab al-Aghani-The Book of songs, in Istanbul, a copy made by Mohammad ibn Abi Talib al-Badri (614Hijri/1217-1218 A.D.). 
Abi Faraj Al-Usfahani's manuscript Songs kept at Istanbul's National Library, Muhammad Abi Talib Al-barda's copy of H.614/A.D.1217.

What primarily draws the attention in the manuscript is the prince's Turkish countenance who is holding an arch and arrow, the symbol of power to the Turks given the consideration that prince Badr Addein is one of the real characters that ruled Al-Mosul, and that is indicated by the inscription of his name on the ribbons wrapping his arms. The main character is sitting in a big size on the throne in the middle of the manuscript wearing an Arabian style embellished with Arabic writings with a turban decorated with the same the style of the Arabic writing, a matter reducing the artist's interest in ratio and proportion between the size of the main character and the secondary ones and their relationship with the surrounding space. To realize the colour-form unity the artist takes care to repeat ladies of a Turkish countenance-with two plaits on both sides-in the background in a simplified way through the use of colour groups represented by the colours, blue, red and gold. Besides, the formal equilibrium is realized through the distribution of the human elements wherein five ladies appear on the right side, and five other ones on the left side wearing dresses decorated with glossy colours represented by the degrees of blue and red. The manuscript is characterized with two external frameworks: an internal one with geometrical embellishments occupying a smaller area, and an external one with botanical arabesque occupying a bigger area.

The manuscript is the most creative of copying because it involves portraits inspired by the animal world and is introduced as a genre of sarcasm ridiculing the situation in society and the ruling class; the animal element is playing a major role within the manuscript to give a proverb of a moral implication (reaching the peak is difficult, but decay is easy). That is shown by bestowing on the animal the quality of looking at the peak and the desire of reaching it, which is clearly seen in the acting position of the two animals that are presented separately in the manuscript so that the drawings can serve the literary text. The artist is using the ground line on which the simplified, superficial animal and botanical elements stand in the form of a horizontal matrix. He is also using the form of trees in the manuscript background in a simplified manner adding textual writings up and down the manuscript with a horizontal distribution to clarify the manuscript text. The manuscript features silence and statics through the acting position of Donah and the lion in spite of the movement of the surrounding plants. The artist is using the glossy colour group represented by the degrees of colours: red, blue and green in addition to the golden background that contributes to the realization of the colour unity.

\subsection{The Persian Manuscripts}

Figure 7 is Yousef and Zalkha-from the book "bostan (Orchard)" by the Iranian poet, Sa'adi-Bahzad 1488-National Book House-Cairo.

This manuscript was written by Sultan Ali, Sultan Hussein Mairza's writer. 


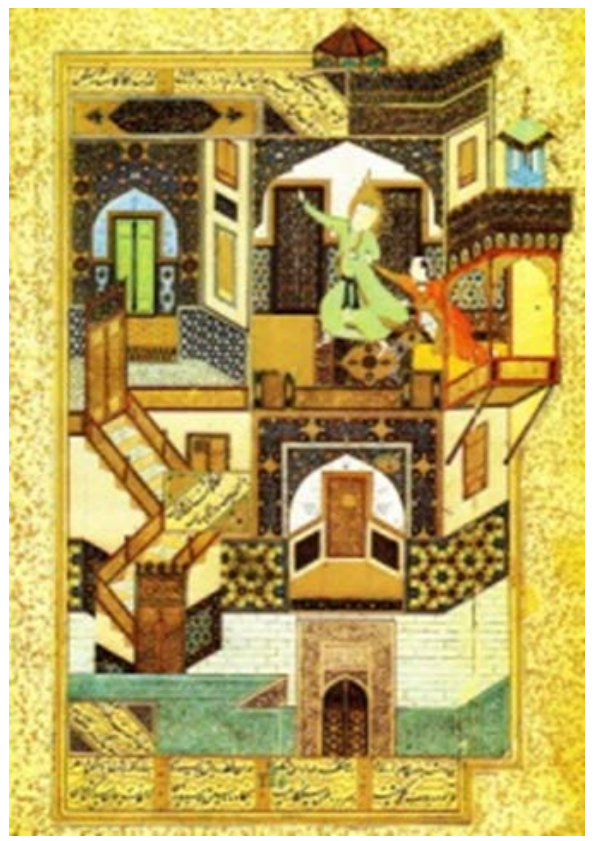

Figure 7. "Yusuf Wa Zulekha", made by Bahzad for the book The Bostan of Saadi (The Orchard) 1488 A.D., Dar al-kutub al-Wataniya (National House of Books), Cairo.

The manuscript features the skill of mixing colours and the proper distribution of the house's various parts from the interior and exterior at the same time in addition to two minarets in the rear. The artist's ability to distribute properly the arabesque areas represented by the calligraphic writings, botanical garnish and star plates inside and outside the building sections, a matter which realizes the total unity of the manuscript elements, which bestows on it a unique, diversified, decorative print.

The artist's departure from the framework designed for the drawing is seen in the addition of writing ribbons divided up and down the manuscript together with the use of implicit, glossy colour degrees. The artist is keen on the balance between his distribution of the calligraphic writings and the garnish elements, effects and touches within the manuscript space, and the uniqueness of the work appears through the artist's handling of more than one place at the same time in the inside and outside (the combination of different spots).

Figure 8 is Majnoon Leyla-from the manuscript collection "The Five" by the Iranian poet, Nethami-John Rainlenders-Germany-16 ${ }^{\text {th }}$ century.

The manuscript portrays Majnoon Leyla sitting on the ground on the left side of the manuscript front near his camels, and in the manuscript background Leyla appears sitting with one of her guards near her in the same size at the rear of the manuscript, which reflects the artist's indifference to ratio and proportion in the distribution of his elements. The uniqueness of this manuscript lies in the artist's handling of a social implication reflecting the story of "Majnoon Leyla", and the colour-form unity is realized through the artist's handling of the elements of the natural environment represented by animals (deer, stags, tigers and lions), trees and herbs, which has contributed to the realization of an organic 


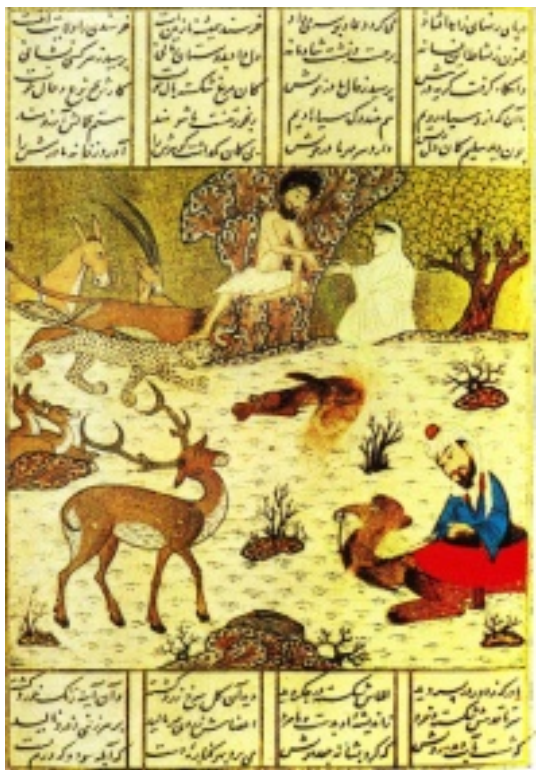

Figure 8. Majnun Leila (The crazy about Leila), al-Khamsa (The Five) manuscript of the Persian poet Nidami, The John Rylands Library-Germany, c 16 A.D.

unity among the manuscript elements besides colour and touch effects of herbs and grass on the floor.

The artist is also keen to realize the colour and dynamic rhythm in his distribution of the colour spaces and the acting postures of the animal elements that formally appear. The artist also presents the literary text of the manuscript in the form of an arabesque ribbon divided up and down the manuscript into square spaces with copying writings inside them to elaborate the manuscript text. $\mathrm{He}$ also used a group of glossy colours represented by the degrees of red, blue and brown. He handled the background with the degrees of the gold colour. The manuscript is dominated by the arabesque print resulting from the effects and touches of every element by itself. Despite the simplicity of the animal elements, we can distinguish every animal category through its formal features and acting postures that elaborate the dynamic aspect of the manuscript in spite of realizing the static aspect resulting from the status of the human element.

Figure 9 shows that Rostum wrestling a dragon-Al-Shah Namah-by Al-Ferdousi-from Muhammad Qassim's works or Muhammad Yousef's-Iran-1648-The Royal Library-Windsor Palace-Britain.

On the left side of the manuscript, Rostum, the hero appears dressed in his military uniform-represented by the shirt and trousers with an animal-shaped helmet on his head-wrestling a dragon holding a protection shield in his left hand and a sword in his right hand to fight the dragon that appears in its superstitious shape. Despite the artist's interest in the size of the hero and dragon that represent the main topic of the manuscript, supremacy is achieved through the forms of clouds appearing in the manuscript background.

The uniqueness of the manuscript is clearly seen in the artist's handling of a social issue reflecting the power of the main character, Rostum. On the right 
side, we see the hero's horse handled almost in a realistic manner. We notice personification in its head and in some parts of its body. The manuscript background is a group of accumulating clouds reflecting a sense of overcrowding, and the linear rhythm is realized through random lines in different directions within the manuscript occupying three quarters of the manuscript space and inspired from Chinese art. The artist uses a group of glossy colours represented by the degrees of yellow, blue and red. The manuscript also contains an incomplete arabesque ribbon of Persian writings in al-naskh (copying) calligraphy.

Figure 10 is the water-porter (The guy and coffee), Reda Abassi's drawing $-17^{\text {th }}$

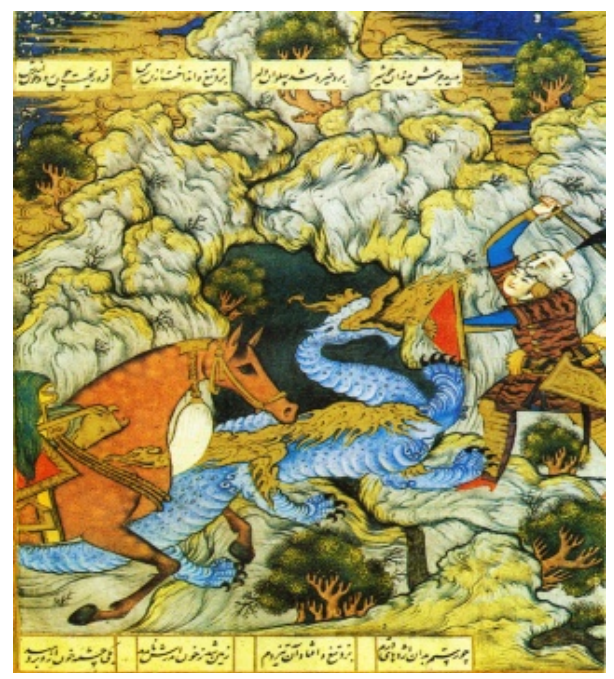

Figure 9. Rostam fighting the Dragon, Shahnameh of Ferdowsi, Mohammad Kacem or Mohammad Yusuf, Iran, 1648 A.D, King's library, Windsor Castle, Britain.

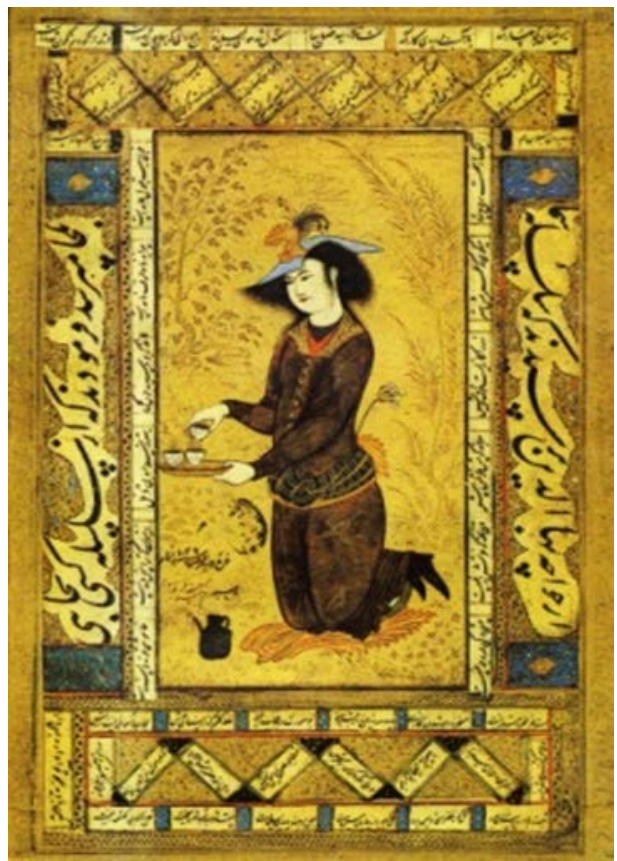

Figure 10. Sommelier (Young man and Coffee), Painting of Ridhâ Abbassi-Seventeeth century (A.D.)-Museum of Tahran. 
century Asfahan-Museum of Arabesque Arts-Teheran.

The manuscript shows a guy with Mongolian features in a sitting posture to introduce a tray with cups on-wearing a shirt, trousers and a hat embellished with feathers. The water-porter's body is handled superficially, and to emphasize the uniqueness of the manuscript, the artist introduces a social value represented by respect of work. In the manuscript background, we notice simple decorations of branches of two kinds of trees. Supremacy is discerned in the manuscript in the main character that occupies three quarters of the manuscript space. Equilibrium is realized through the posture of the water-porter's hands and legs and the branches in the background. A number of ribbons are seen with Persian writings in al-naskh calligraphy inside them that contribute to the realization of the linear rhythm and equilibrium with the main character. The artist uses a colour group of brown and blue degrees in small amounts and gold which takes up the background space.

Figure 11 shows Muhammad's night travel on horseback-Al-Byroni's book Remaining Relics-Edinburgh University.

The Prophet's portrait (pbuh) shows him on a horseback with a flare-shaped aura around his head emitting light, and surrounded by figures of winged angels with Chinese features, and a group of superstitious creatures scattered around the horse ridden by the Prophet (pbuh). The work features uniqueness through the artist's handling of the Prophet's body with no details of the body and face features. The supremacy of the manuscript is seen through the artist's way of handling the main character, the Prophet in a bigger size and in the middle of the manuscript. To stress the colour unity, the artist uses the colour degrees of red, blue and gold in the elements drawn inside the manuscript. He also manipulates

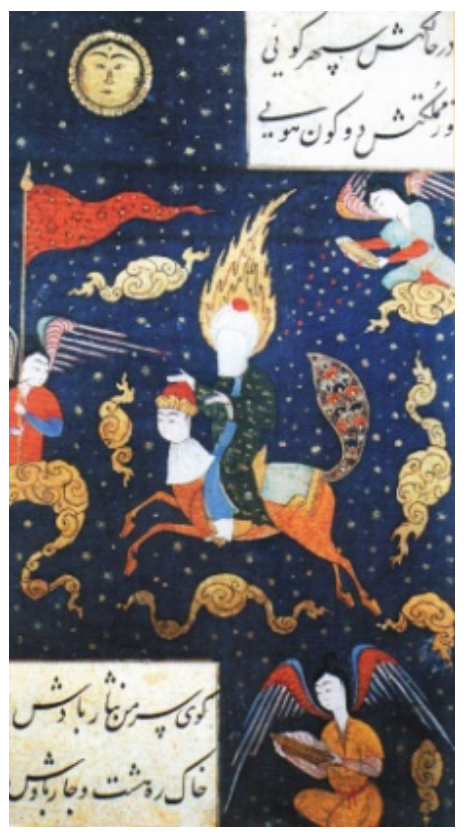

Figure 11. Mohamed al-Laili trip on the Bouraq's back, the book of Biruni, Adanbara University. 
the background with dark blue decorating the sky with golden stars. He also uses Persian writings on the right side of the manuscript to clarify the text, thus realizing formal equilibrium with the drawn elements.

\section{Research Conclusion and Recommendations}

As a conclusion, the researchers provide a comprehensive introduction to Islamic Painting Manuscripts, which they have succeeded in identifying some artistic and aesthetic characteristics especially for Arabic and Persian schools and styles. This research includes analysing of 11 manuscripts artworks from both Arabic and Persian models, which contributed in crystallizing and explaining the Islamic Manuscript painting characteristics, especially in English language. In general, the research results led to the following conclusion:

1) Identifying exceptive characteristics for both Arabic and Persian Manuscript paintings, which someone could distinguish one from the other.

2) The principals of art and design can be found in both manuscripts which reflecting the level of Muslim artists understanding.

3) Both Arabic and Persian Manuscript paintings reflecting high level of artistic and aesthetic values with references to Islamic culture and heritage.

With understanding that there is a lot of effort trying to enhancing teaching art and design education within frame of Islamic art and heritage such as study of (Al-Yahyai, Al-Amri, \& Abudaladul, 2010) which suggesting teaching program for appreciating the aesthetics criteria for the Manuscripts art, with its implementations on the students' art productions at Sultan Qaboos University as well as studying the works of Contemporary Omani Artists in terms of Islamic identity in the Globalization era (Al-Yahyai, 2011), there is a need to do more. The current research recommends the following points based on the results and discussions of this research:

1) There is a need for improving the appreciation abilities towards Manuscript painting Islamic Art in general and in the Arabic and Persian Schools in particularly.

2) There is a need to introduce this kind of Islamic art to students, art educators and researchers, worldwide, in order to activate Islamic art culture and heritage.

3) The necessity to adopt theories and practices when teaching any art discipline of Islamic Arts.

4) There is a need to do some comparative studies among Islamic Manuscripts based on artistic, aesthetics and characteristics values.

\section{Conflicts of Interest}

The authors declare no conflicts of interest regarding the publication of this paper.

\section{References}

Abdu, M. A. (1987). Contemporary Vision of the Book Kalila and Dimna. Unpublished 
Doctoral Dissertations, Cairo: Faculty of Fine Arts, Helwan University.

Abu-al-ânin, M. (2000). The Cognitive Connotations of Space in Selected of Two Dimensional Contemporary Artworks as Input to Enrich the Decorative Designs. Unpublished Doctoral Dissertations, Cairo: Faculty of Art Education, Helwan University.

Alam, N. (1982). Middle East Art in Islamic Era (34rd ed.). Cairo: Dare Alfiker Publisher.

Al-Amri, M. (2019a). Art and Design Education in the Middle East and North Africa: A Brief Historical Overview. In R. Hickman, J. Baldacchino, K. Freedman, E. Hall, \& N. Meager (Eds.), The International Encyclopedia of Art and Design Education (pp. 1-15, Volume 1). Hoboken, NJ: John Wiley \& Sons. https://doi.org/10.1002/9781118978061.ead116g

Al-Amri, M. (2019b). Islamic and Other Influences on Art and Design Education in the Middle East and North Africa. In R. Hickman, J. Baldacchino, K. Freedman, E. Hall, \& N. Meager (Eds.), The International Encyclopedia of Art and Design Education (pp. 1-9, Volume 1). Hoboken, NJ: John Wiley \& Sons. https://doi.org/10.1002/9781118978061.ead055

Al-Bahnasi, A. (1997). Art Criticism and Reading Pictures. Cairo: The Arabic Book Publishing House.

Al-Basha, H. (1988). Data-Based on Islamic Art and Architecture. Cairo: The Arab Renaissance Publishing House.

Al-Basha, H. (1990). Approach to Islamic Archaeology. Cairo: The Arab Renaissance Publishing House.

AlNachar, N. (1978). Repetition in Selected Modern Paintings and Its Educational Benefits. Unpublished Doctoral Dissertations, Cairo: Faculty of Art Education, Helwan University.

Al-Sayg, S. (1988). Islamic Art: Reflective Literature Review in Philosophy and Aesthetic Characteristics. Beirut: Dar Al-Marefa Press.

Al-Yahyai, F. (2011). The Works of Contemporary Omani Artists \& Its Role in Expressing Islamic Identity in the Globalization Era. Researches in Art Education and Arts, 32, 202-225.

Al-Yahyai, F., Al-Amri, M., \& Abudaladul, E. (2010). A Suggested Teaching Program for Appreciating the Aesthetics Criteria for the Manuscripts, and Its Impact on the Students Art Productions at Sultan Qaboos University. Researches in Art Education and Arts, 30, 376-433.

Anani, M. (1998). The Chosen of the Letters of the Brothers Safa and Khalan Wafa. Cairo: The General Egyptian Book Organization.

Attia, M. (1997). Aesthetic Value in Contemporary Plastic Art. Cairo: Dare Alfiker Alarabi.

Attia, M. (1999). Aesthetic Value in Contemporary Plastic Art (2nd ed.). Cairo: Dare Alfiker Alarabi.

Attia, M. (2005). Topics in Islamic Arts. Cairo: Alam Alkotob.

Bosworth, C. E. (1996). Islamic Dynasties. New York: Columbia University Press.

Bronowski, J. (1981). The Ascent of Man (Translated by Shakhashir, M). Kuwait: Alam Al Ma'rifah Publisher.

El-Bassiouny, M. (1994). Secrets of Plastic Arts. Cairo: Alam Alkotob.

Farghali, A. (1991). Islamic Painting: It's Establishment, the Position of Islam, Origins and Schools (pp. 84-86). Cairo: El Dar El Masria-Lebanese.

Hamouda, M. (1994). The History of Islamic Book Manuscript. Cairo: Gharib Publishing 
House.

Hanoura, M. (1997). Artistic Creation, Your Book Series. Cairo: Alam Al Ma'rifah Publisher.

Hattstein, M. (2000). Islam: World Religion and Cultural Power. In M. Hattstein \& P. Delius (Eds.), Islam: Art and Architecture (pp. 9-31). Cologne: Konemann.

Izzat, I (2006). Artistic and Philosophical Orientations in Persian Literary Manuscripts' Paintings as an Inspiration for Contemporary Artworks Dedicated to the Children. Unpublished Doctoral Dissertations, Cairo: Faculty of Art Education, Helwan University.

Mehrez, J. (1962). Islamic Painting and Its Schools. Cairo: Ministry of Culture and National Orientations, The General Egyptian Book Organization.

Okasha, Th. (1977). Islamic Painting (Volume 4). Beirut: Arab Institute for Research \& Publishing.

Sabri, A. (2000). Artistic Values in Islamic Manuscripts in Arabic and Persian Schools: Comparative Study. Unpublished Master's Thesis, Cairo: Faculty of Art Education, Helwan University.

Shelquist, R. (2018). Al-Musawwir. The Beautiful Names of Allah. https://wahiduddin.net/words/99_pages/musawwir_13.htm 